\title{
Public Communication Conflicts Between the Central Government and the DKI Jakarta Government in Handling the Covid-19 Pandemic
}

\author{
Ana Windarsih ${ }^{1}$ \\ ${ }^{I}$ Research Center for Society and Culture, Indonesian Institute of Sciences \\ ${ }^{*}$ Correspondence Email: ana.windarsih@gmail.com
}

\begin{abstract}
Since it was announced that there was the first Covid-19 case on March 2, 2020, Indonesia is currently entering its 7 th month. The number of cases continues to increase eventhough various restriction policies to prevent transmission have been implemented. For more than one semester there has been no policy that is felt to be effectively integrated between the central government and local government especially the capital city of Jakarta (DKI Jakarta). There are always criticism and differences, including how to communicate the policy to the public. The aim of this study to examine the effectiveness of large-scale social restrictions (Pembatasan Sosial Berskala Besar/PSBB) in DKI Jakarta which are always considered to be against the central government. The data was collected from Instagram (IG) during the first PSBB policy on mid-March 2020 until the PSBB policy is tightened again in mid-September 2020. By using social network analysis (SNA), it shows who the actors and their relations with the PSBB. Interestingly, although it seems contested, there are also evaluations and negosiations between the central government and DKI Jakarta government even though implicitly. As a result, conflict that often arise, even if only in terms of communicating policy, that has the potential to reduce effectiveness and public trust.
\end{abstract}

Keywords: public communication, conflict, the large-scale social distancing (PSBB), central government, local government (DKI Jakarta)

\section{INTRODUCTION}

APJII 2018 data for Instagram (IG) users ranks 2nd most frequently visited internet content (social media) at $17.8 \%$, after Facebook (FB) which ranks first at $50.7 \%$ [1]. Twitter only ranks 4th with a total of $1.7 \%$. This is confirmed by the results of Hootsuite's research that the aggregate level of media use of all companies tends to use IG (100\%) to promote of media assets [2]. IG itself in its business web page mentions an increase in $82 \%$ in the time spent watching video on IG [3]. The tendency to use resources of social networks as a source of data also increased lately, since the functions that can be used to predict performance [4], the relation of communication between users of social media [5], as well as sentiment analysis.
There are three things that affect research digital phenomenon: philosophy, methods, and ethics. In the philosophy of virtual research with online method the researcher as well as a user [6]. In this context researchers also only describes the events online. In a pandemic situation this method of choice. Research data sources on Twitter is growing, while Instagram has not been widely explored. This study fills a gap that has not been done by researchers of social media. 'A picture depict thousand word'. The picture playing a very importance role in exploring human society, public affairs, etc. [7]. And by IG provide new means to judge the public opinion and generates feedback in real time which is more valuable and gives better response as compared to radio or TV broadcasting [8]. 
This paper aims to explore how public communication conflicts related to the handling of pandemic Covid-19 especially the large-scale social distancing (Pembatasan Sosial Berskala Besar/PSBB) policies between the central government and the Jakarta government through social media Instagram. IG attract a lot of users because it looks interesting, featuring images and infographics compact even videos [9]. The Twitter dataset that was crawled with Netlytic [10] was carried out to determine the communication relationship between users. Submission of information and government policies thus matching the style of which is currently the millennial age group the largest social media users. Demographic bonus as well as a digital blessing.

Conflicts public communication in managing the pandemic Covid-19 related measures taken very appreciated from the IG. This is evident from the like and comments that appear on each upload content that contains the IG central Government policies and Jakarta as a pouch case Covid-19. The response from users also seem to be considered by the government to evaluate policies are applied. Not infrequently appear IG content-laden response improvement of government policy, having previously appeared in the IG content that shows different views (read: conflict) between the central government and the government of Jakarta.

\section{LITERATURE REVIEW}

Expression in the digital space including Instagram is increasingly becoming epidemic, especially for millennials who were born digital. It is increasingly becoming during a pandemic that requires physical distancing and crowd restrictions. Initially, about five years earlier, several tools such as Netlytic, Facepager [11] provided machine learning data collection facilities for Instagram, but when this research was carried out it changed. Even if traced deeper, the removal of this facility is because it was taken over by the Instagram platform itself through its Instagram business. It seems that Instagram provides its own selling point to attract investors or make customer analyzes of both their behavior and consumption patterns. On the other hand, this limits the space for researchers to gain access to data retrieval freely and without strict restrictions. Several studies have been inspired to optimize algorithms that are able to solve problems [12] for free and open source tools [13]. The automation of IG activities is actually very helpful for researchers to analyze [14]. Digital data in a virtual space that is unlimited in time and space is rapidly changing and increasing.

The more the activity grows toward virtual, the more it will encourage researchers and academics to develop methods of interpreting social media networks. For Twitter up to this research, tools that can be used as a tool for social research have grown. From data collection, data cleaning to analysis of both text, social network structures, and visualization of relationships and networks between users. Various tools are offered to produce valid datasets, some are paid, but also many are open access as mmds.org [15]. The research conducted by scholars also supports the development of research towards various social media platforms using the social network analysis method [16].

Tracing works devoted to documenting the surrounding pandemics that occurred in the past such as the Spanish flu, some works are analogous to literary or artistic writing. Even Zizek [17], during the Covid-19 pandemic, recorded a pandemic accompanied by the writing of local stories which could then be made global. Webbs [18] cites pandemic events such as the Black Death. Through the literary or art writing model, society will be easier to accept and understand because in literature there are no demands and compulsion. 
People who witness will voluntarily and do not feel burdened. Psychologically [19] will give a lot of meaning to his readiness for adaptation to face a pandemic which is full of uncertainty and immunity of each person [20], [21].

The pull of interest during a pandemic also continues to haunt you. Either health or economic priority. Sometimes political forces also emerge which greatly affect the credibility of the government in determining and implementing policies to deal with pandemics. In several instances, the absence of accurate public communication has resulted in contradictory statements between the government and the public [22]. Due to the lack of coordination between government elements it also sometimes generates a widespread response among netizens. Management of information and data related to the Covid-19 case that is not sourced at one door and the limited number of experts who are willing to actively speak out using the media [23] have led to the emergence of hoaxes [24]. Cooperation between countries at the global level is limited because everyone experiences the same thing. All countries struggle to protect themselves from Covid19 by prohibiting their citizens from visiting other countries or if allowed to comply with the standard covid-19 protocol. For example, the US even stated that it stopped supporting WHO because it was a country with a high death rate due to Covid-19. As in previous events, if the war is over or there are major changes in the world, then there will definitely be a reconstruction of the global cooperation order.

\section{METHOD}

This study used a qualitative approach. Content IG account katadatacoid (@katadatacoid) observed that contain communication differences between the central government and the Jakarta administration. Of the total content uploaded been associated with the theme. Then analyzed in a narrative. Dataset taken from Twitter also taken (crawling) using Netlytic. Twitter data is intended to complement relations between actors involved in communication on the PSBB theme.

The study is conducted in a virtual digital, so the data obtained is online data. From a total of 5836 amounted content observed and election-related content themes. The result was around 600 posts related to themes covering policies carried out by the central government, in this case represented by the president, vice president and ministers as well as the governor of DKI Jakarta and their local government officials (Pemerintah Daerah). Then from the 600 s the data was cleaned again to get data that really represented the theme. Meanwhile, Twitter data was collected on October 27, 2020 with a website-based Netlytic device. The data was collected as many as 1,000 by keyword PSBB OR DKI Jakarta data withdrawal. The analysis can be done using Netlytic at once, because Netlytic provides tools for data collection, data processing and data analysis.

As the unit of analysis is the media organization through the IG account @ katadatacoid and institutions/ministries, the official IG account of the governor of DKI Jakarta as well as the president as head of government. Also the Twitter platform.

The reason for choosing IG media through the @ katadatacoid account is because it is a media that provides data on a research basis. However, to obtain data triangulation, the researchers also made observations on several IG media accounts and official IG accounts of President Joko Widodo and Governor Anies Baswedan (see Table 1.)

The type of data collected is in the form of image screenshots, infographics or videos uploaded via the @ katadatacoid account. 
Meanwhile, data from Twitter is in the form of a dataset that includes various things, such as Twitter users, relationships between users, user accounts, etc. To maintain research ethics for this data collection the researcher followed all observed accounts. As for using Netlytic, researchers must have a Twitter account if they want to mine Twitter data and register an email account to be able to access and get the dataset for free.

The time for data collection was carried out from the implementation of the first PSBB policy until the transitional PSBB ended on September, 10, 2020. The strict PSBB from mid-March 2020 to early June has been extended by 5 times. Meanwhile, for the PSBB, the transitional period was extended 3 times from early June to early September 2020.

The research was conducted with the Covid-19 pandemic situation. The choice of digital method becomes imperative amidst strict large-scale social restrictions and transitions. With the digital method it is possible to do everything online. There are 7 IG account that are followed to obtain data as the table below:

\section{Table 1. Account Address Observed in} The Research

\begin{tabular}{|c|c|c|c|c|}
\hline $\begin{array}{c}\text { IG } \\
\text { Address }\end{array}$ & Post & Follower & $\begin{array}{l}\text { Follo } \\
\text { wing } \\
\end{array}$ & Information \\
\hline $\begin{array}{l}\text { @ katadata } \\
\text { coid }\end{array}$ & 5.836 & 263.000 & 179 & $\begin{array}{l}\text { Integrated news, } \\
\text { data and } \\
\text { research portal }\end{array}$ \\
\hline $\begin{array}{l}@ \text { tempodo } \\
\text { tco }\end{array}$ & 8.560 & 519.000 & 72 & $\begin{array}{l}\text { Tempo Media } \\
\text { Group } \\
\text { \#tempodotco } \\
\text { \#majalahtempo } \\
\text { \#korantempo }\end{array}$ \\
\hline $\begin{array}{l}\text { @ kompasi } \\
\text { ana }\end{array}$ & 2.196 & 95.200 & 62 & $\begin{array}{l}\text { \#BeyondBloggi } \\
\text { ng| Citizen } \\
\text { News and } \\
\text { Opinion } \\
\text { Channel }\end{array}$ \\
\hline $\begin{array}{l}\text { @ kumpara } \\
\text { ncom }\end{array}$ & 15.935 & 1.100 .000 & 3 & \\
\hline @ tirtoid & 5.101 & 993.000 & 15 & $\begin{array}{l}\text { Data Jurnalism, } \\
\text { media analysis, } \\
\text { infographics. } \\
\text { Article } \\
\text { resources \& } \\
\text { podcast }\end{array}$ \\
\hline @jokowi & 2.283 & 36.300 .000 & 0 & $\begin{array}{l}\text { Official } \\
\text { Accounts } \\
\text { Presidential }\end{array}$ \\
\hline
\end{tabular}

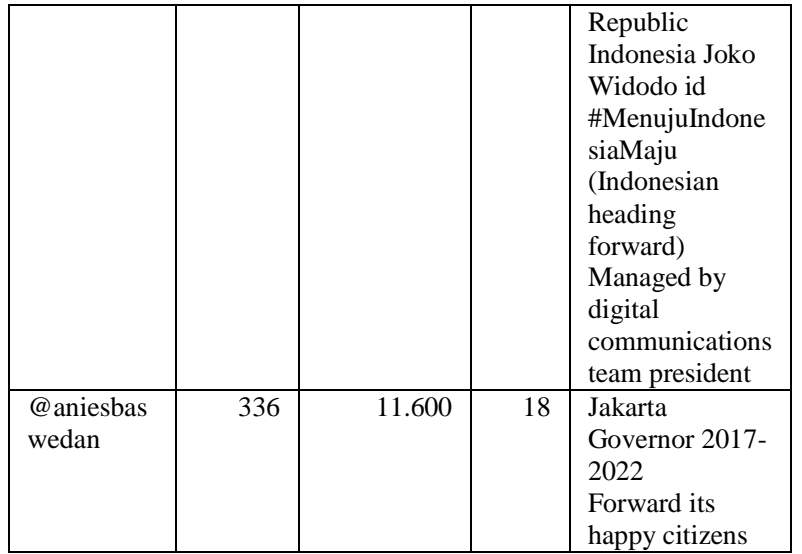

But only@katadatacoid the depth and detail what is used in this study. This is because of the limitations of authors have not found a tool that can automatically collect data from Instagram. Once there apparently virgin Netlytic leak case that was originally allowed to be used as a means of limiting the data crawling amenities.

The analysis that will be used is descriptive narrative and interpretive analysis of the existing content in the @ katadatacoid account. The analysis of the dataset provided by Netlytic Twitter already, so just write the result.

\section{FINDING AND DISCUSSION}

The results of the observations from the @ katadatacoid account are as follows:

President Joko Widodo's statements vary and lead to different interpretations on social media. Some examples of statements during the transitional PSBB period:

Health interests are the top priority. Uploaded on September 7, 2020. The post received a response from netizens of 1,734 likes and 87 comments: 


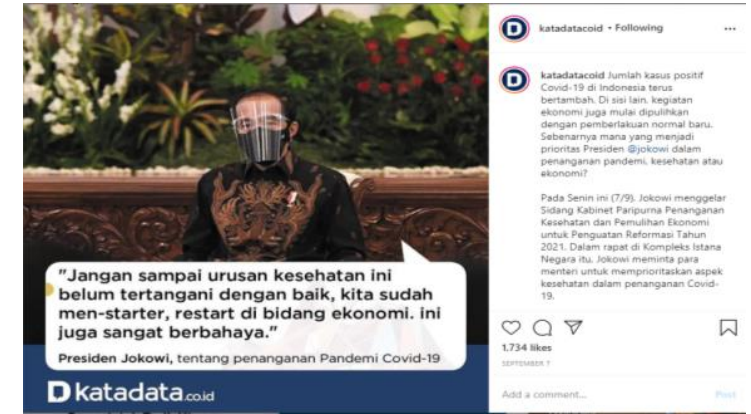

The number of 'likes' from the community shows concern for health issues

Then, statements in a political context uploaded on 4 September 2020 received 1,557 likes and 66 comments below. Jokowi seems to respond to public questions about the performance of the ministers during a pandemic. Some people say that there are ministers who have been reshuffled due to lack of performance.
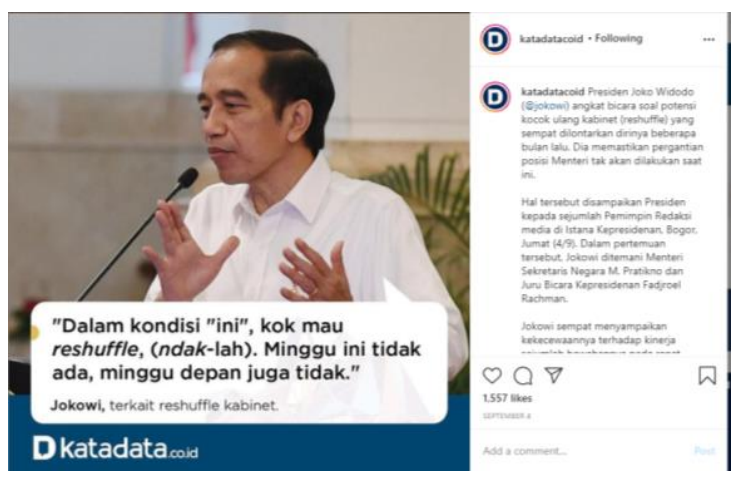

Further, the president's statement can have different meanings among the public and his assistants as well as local governments, especially DKI Jakarta. uploaded on August, 26, 2020 has 1.368 likes. The President emphasized that local governments in handling Covid-19 must coordinate with the central government. This statement seems authoritarian because each case is different. However, it must be understood that the command must be at the center although its implementation can be more flexible according to the conditions of each region.

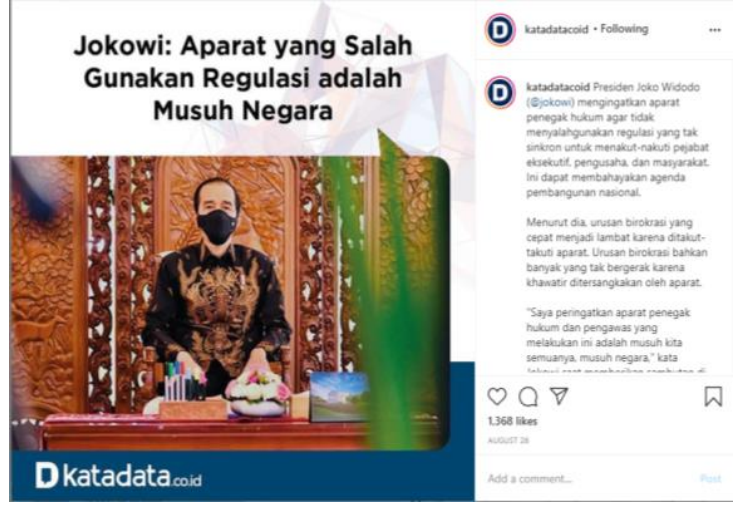

Uploaded on August 22, 2020, stating the ability of the Jakarta government to provide tests related to Covid-19. There are 439 likes, 4 comments. The statement below provides an estimate of the ability of the regional government specifically for the capital city of Jakarta to carry out daily covid-19 tests. So that it is hoped that the public will better understand the conditions, be alert and always be disciplined in the Covid-19 protocol.
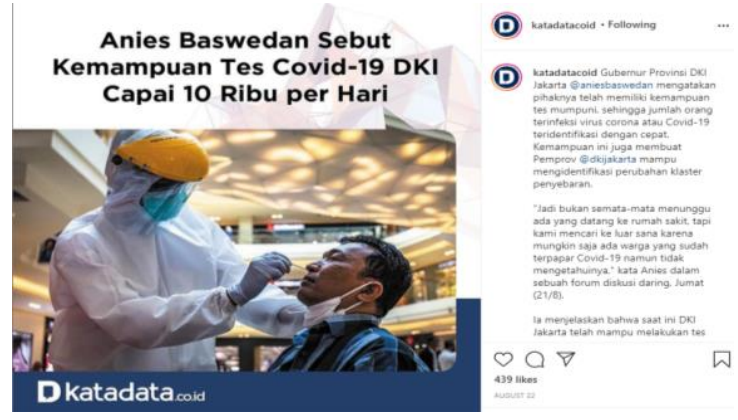

A statement from one of the coordinating ministers led to various polemics. The government response was uploaded on 10 September 2020 with a response of 1,452 likes, 93 comments. The coordinating minister for economy stated that the office could still be open even though the DKI Jakarta government stipulated the PSBB. It seems that economic interests must be considered in order to keep people's lives moving. 


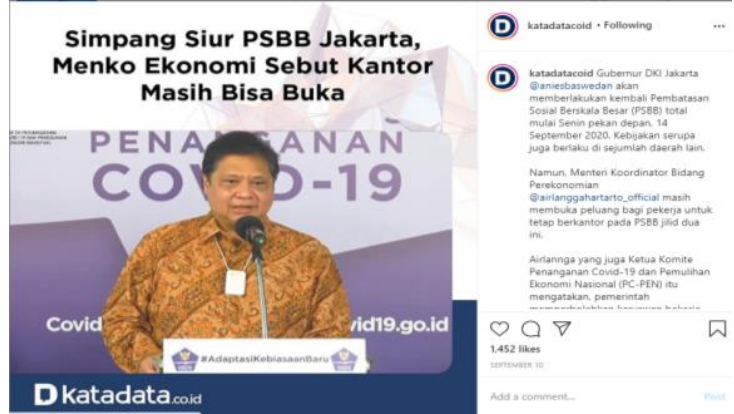

There are also the task force provided a statement that contained anxiety and uncertainty. So there are only 534 likes:

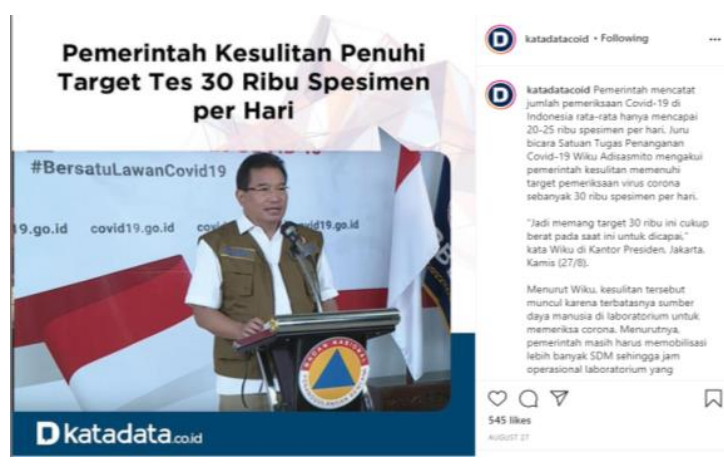

The task force for handling covid-19 should always provide enlightenment and optimistic information to the public because it can mobilize all resources to carry out its mission.

Next upload, as the capital of the country where the stock exchange is located, the response to the PSBB policy is related to its impact on the sustainability of the macroeconomic trading floor. There are 664 likes:

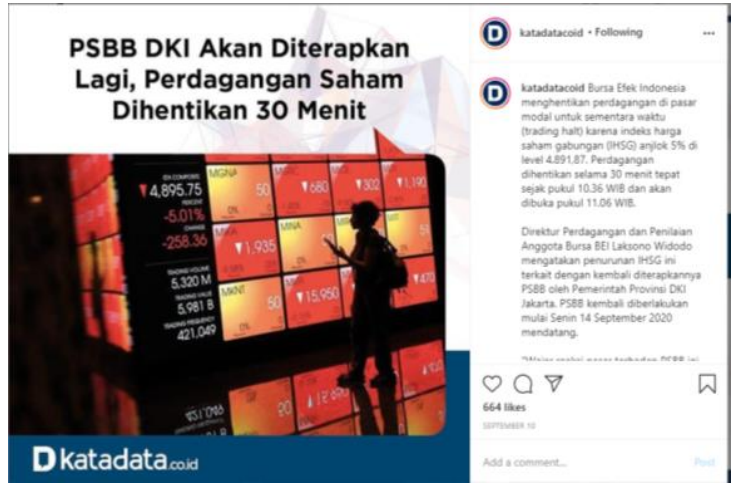

The viewpoint of UI academics emerged who conveyed the results of their research in a webinar organized by Kata Data.
Uploaded on August 25, 2020. Public awareness must be understood that there is a burden on the nation's future generations.

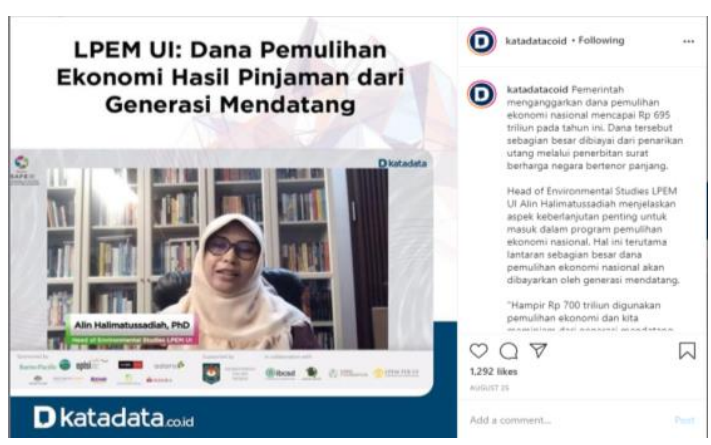

Development of vaccine research update on August 22, 2020. There are 646 likes, 10 comments. Vaccine research efforts continue to be pursued, but in fact the vaccine is not the only single solution handling covid-19. The cooperation of all parties is needed to be able to overcome the Covid-19 pandemic.
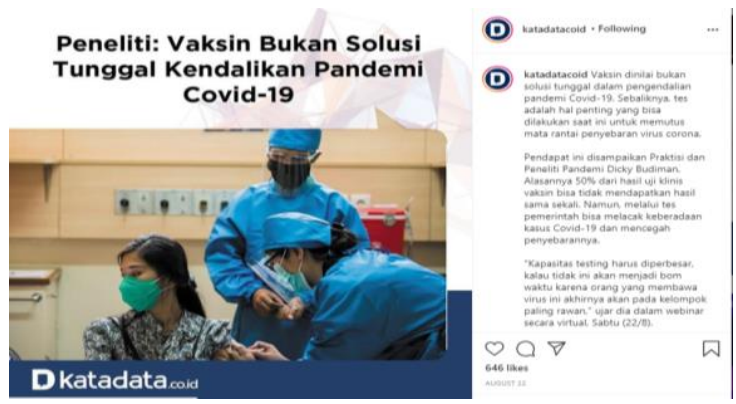

Sometimes proposal or response to the government also decided through a series of discussions on the various elements of society. Jakarta as the central office is closely related to the buffer area (Jakarta, Bogor, Depok, Tangerang dan Bekasi/Jabodetabek), so it is important to make one command for the handling covid 19 more optimal. 


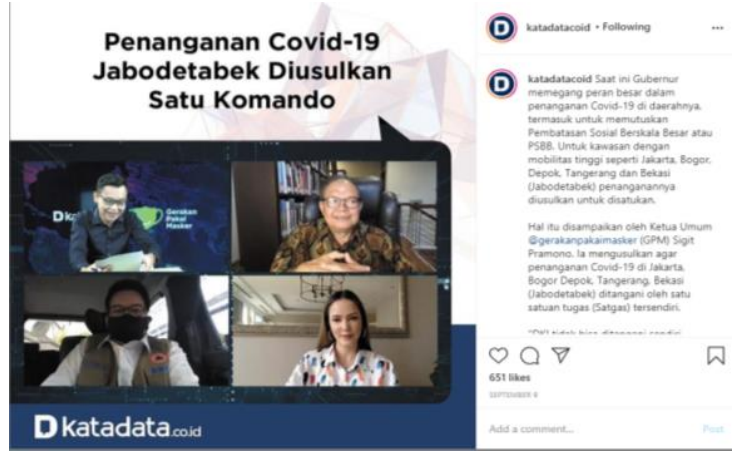

In addition, it also could see the level of participation, efforts and understanding of the community.

Examples of other cases that hit workers. Public response from the wider community regarding the possibility of termination of employment. The government must prepare appropriate policy schemes together with local governments to avoid layoffs.

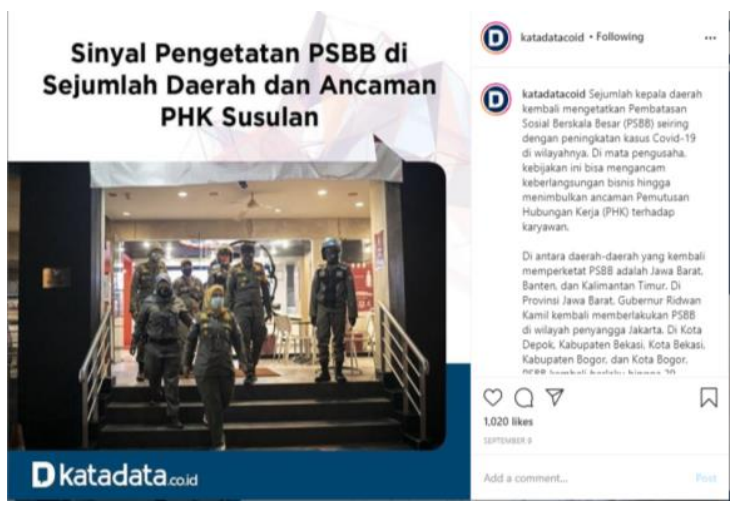

Selected from uploads that have likes/ views/comments above 4 thousand. Statements that show conflicting impressions between the central government and the DKI Jakarta government regarding the implementation of the first PSBB policy (March - early June 2020) can be seen in the following table.
Table 2. Themes, Likes/Views, and Comments

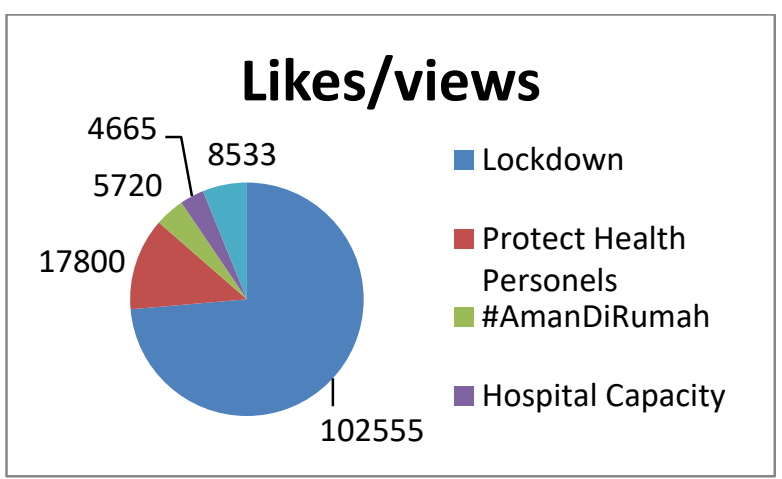

Every upload related to policies and steps to implement government policies always gets a response from IG users. The response is done in real time, so that it can be a quick consideration for further policy input. How strong is the response submitted can be seen from the likes of the uploaded content. On average, more than 500 people are even more than 1000. Uploads with IG video formats always get views that far exceed the response of uploads with photo or infographic formats (see Table 2). The screenshots above only represent the responses of various parties to the uploaded content and show the forms of polemic which are sometimes contradictory between various elements including the governor of DKI Jakarta. Furthermore, a representation of themes that often get big responses will be presented in the form of pie charts.

From these results it can be concluded that at the beginning of the pandemic, the government and society were in confusion. However, the community seems to be able to adapt first and create resilience with the social capital they have. This is evidenced by the real-time response that can always make the government listen and consider the demands and responses that are submitted. Meanwhile, on the government side, it is a bit slow if not too late. It seemed that the policy decided was just patchy, as if the exterminator would quickly end. The inaccuracy of the data in the database has caused difficulties in 
distributing basic necessities and direct cash assistance. Information related to the case of personal identity as if it was not open and very closed, causing unrest in the community.

To complement and compare with other social media platforms collected data from Twitter. By using Netlytic on tier 2 of the 1000 tweets there are 912 unique posts. The results of mining Twitter data with the Netlytic device are shown below.

\section{Top 10 words}

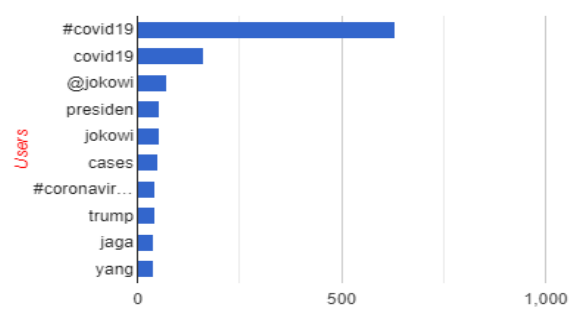

Top words indicate the words that are most frequently typed in the network. In these results, there were words that most frequently tweeted using the hashtag or hashtag \# covid19, followed by covid 19, then the account @jokowi then the president.

Top words indicates the themes that tweeted the most on the network. In such a position, it can be interpreted that actually government always gets respon from public. The responses uploaded can be in the form of criticism, opinion or suggestion, so that they can guide the government in reading the public's wishes in deciding policies.

\section{Top 10 posters mentioned in Messages}

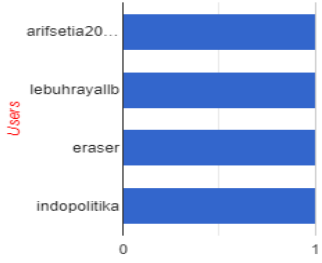

It means that the posters most mention in messages on the network. In the results shown above looks@arifsetia2013d, @1ebuhrayallb,@ @eraser, and @indopolitika accounts have a value equal mention, namely 1 mention.

\section{Top 10 posters}

In the results shown the percentage of each upload. The highest percentage shows $17.8 \%$ followed by second $13.3 \%$ and the third $11.1 \%$ (there are two accounts). The next percentage is $8.9 \%$ with 3 accounts with the same percentage value. The remaining three accounts (CANALABIERTO, WUNIKid and Arlette6523) with a value of $6.7 \%$. The highest upload with $17.8 \%$ shows dominance across messages (1.000) with 912 unique posters. When tracked this account (ab47973330) is quite active tweeting.

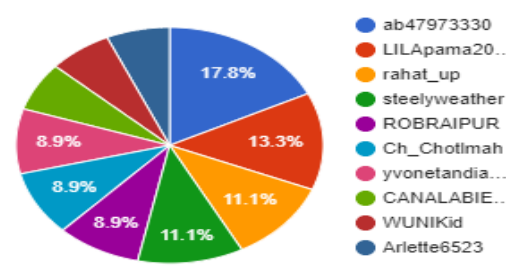

\section{Indegree}

Indegree in the results below shows the strength of the actors in the network of each group. Groups are formed into 5 largest groups which have their own specific theme. The analysis results mention@jokowi as the highes indegree. 


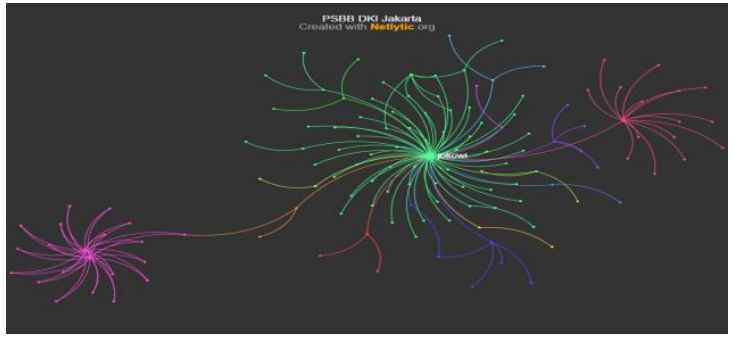

\section{Outdegree}

Meanwhile, the outdegree in the results below shows the strength of the actor in relation to other actors outside the network. The analysis results mention @ibrahimarsyad16, @madurisardesai, and @ alamgirmantasha as outdegree.

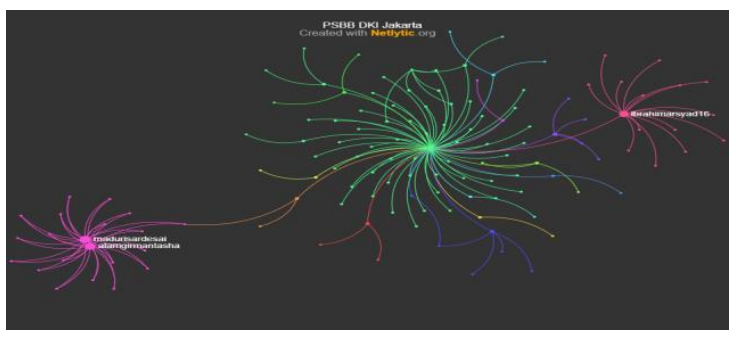

\section{LGL Layout}

LGL layout shows the results of the relations between actors in the network. In these results, there is a relationship between groups indicated by lines connected to each other with different colors. Different colors mean that actors or network users communicate and relate about certain themes or tweets. Very effective for visualizing large network.

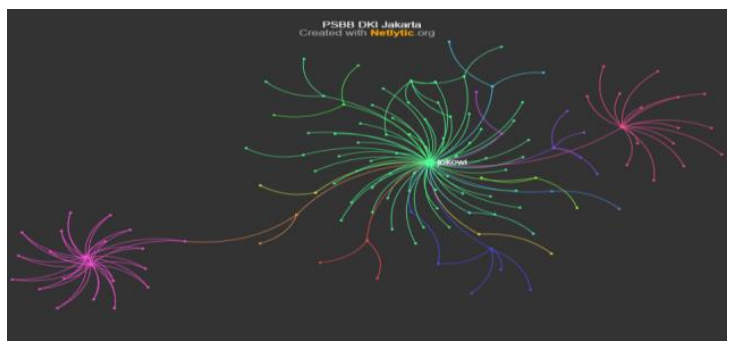

\section{DrL Layout}

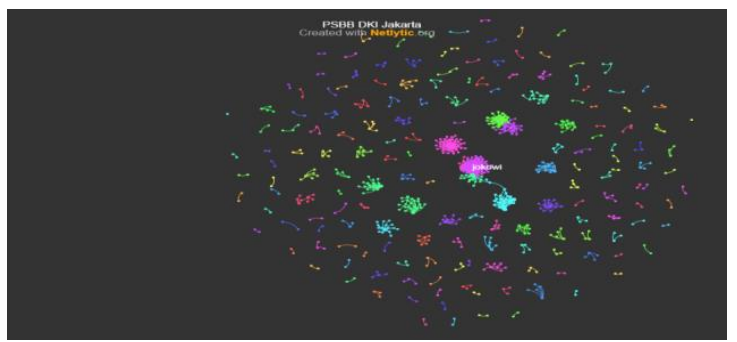

DrL layout shows the results of nodes or actors in the network. Another forcedirected graph layout. Long edges are cut to highlight clusters. But also effective for visualizing large network.

As a final discussion on the findings of this study it can be revealed that the goverment as policy maker still have credibility in implementing their policies. But, it can also be interpreted that the government has the highest influence in relation to the PSBB policy or are not credible in determining policy. That in circulation shows the emergence of differences in communication to the public is very closely influenced by the context. The context of political interests really colors the public's response to every policy launched. This can be seen from the number of likes, comments and views of uploaded content.

From the community side, it can be interpreted that a mechanism for conveying aspirations and self-expression as well as groups has been created through responses on Instagram. Some have also proven to have received good feedback by reviewing the policies that have been decided. Just because IG and Twitter channels or social media are generally free, so that irregularities or hoaxes do not arise, literacy is necessary so that life in the virtual space becomes more orderly and of quality.

Challenges ahead of various changes in life order are turning online. Based on adaptation experiences during the Covid19 pandemic which according to various information will not end quickly, in one 
sense it is a blessing. Like it or not, we have to learn and step by step changing in order to create new habits that have endurance. The model of government and its apparatus must also change the mindset that every policy taken involves public participation. Various changes have emerged during the pandemic and are pointing towards goodness. Digital life provides a space for transparency by keeping a digital footprint.

\section{CONCLUSION}

The contradictory statements are closely related to the politicization of the policies taken. At the beginning of the Covid-19 pandemic, it was felt that all were full of uncertainty and stuttering of all elements, both government and citizens in facing the outbreak. However, over time the adaptation began to bear fruit, the community showed social capital solidarity from below, including the public's response to government policies through their activities on social media Instagram and Twitter. The government has begun to organize itself and take advantage of the real time response of the community in responding to established policies. Some examples of this policy adjustment concern public facilities such as transportation, service to update data on covid-19 cases, update on vaccine developments.

Instagram is an expression space for millennials, so the results of this study are important to fill the basic position of information. As the next generation, the nation's relay needs to be prepared and given space to express themselves and their participation.

The method used in this research is purely virtual or online which is suitable for the situation and context of the Covid-19 pandemic. The phenomenon that occurs in cyberspace is increasing sharply, so the method used must also be strengthened. The challenge of being able to carry out collaborative research will facilitate and deepen research results.

In this research, there has not been a formal collaboration with other disciplines. However, because digital methods are rapidly developing and changing frequently, discussions and sharing are also held informally with several researchers from the digital community research team if the researchers encounter difficulties.

Research limitations in this article are several. First, the selection of Instagram data is actually very interesting, but many tools that can initially be used to mine data automatically eliminate this facility. The drawback of collecting data using manual methods is time and energy consuming. To be the challenge for future research to be able to use automation-based devices. Second, because during a pandemic, digital research is more likely. Moreover, in the future, the phenomenon on social media in particular and the internet will be increasingly attractive and diverse. To facilitate digital research work, it would be better if collaborating across disciplines, including with data scientists.

\section{REFERENCES}

[1] https://www.apjii.or.id/content/read/39/ 410/Hasil-Survei-Penetrasi-dan-PerilakuPengguna-Internet-Indonesia-2018

[2] https://hootsuite.com/research?business $\underline{\text { Size }=\text { all \&industry }=\text { all }}$

[3] https://business.instagram.com/gettingstarted?fbbclid=IwAR3MP1fv58GeEynV U4uDOpXuG9zqiiZBDTk_ZVYaAYcBa L7tyiPY4tNKfOE

[4] I. Smirnov, 'Predicting PISA Scores from Students' Digital Traces', in Proceedings Of The Twelfth International Conference On Web And Social Media, American Association for Artificial Intelligence (AAAI) Press, pp. 360-364, 2018 in E. Komotskiy, et al. 'Analysis of 
Student Educational Interest Using Social Networks Data', W. M. P. van der Aalst et al. (Eds.) AIST 2019, LNCS 111832, pp. 257-264, 2019. Springer Nature Switzerland AG 2019 https://doi.org/10.1007/978-3-030-37334$\underline{4 \_23}$

[5] M. A. Russel and M. Klassen, 'Mining the Social Web Data Mining Facebook, Twitter, Linkedin, Instagram, Github, and More', Third Edition, CA: O'REILLY

[6] A. Seto, 'Praktik Etnografi Digital \& Penerapannya dalam Publikasi Ilmiah', presentation in The Digital Method Workshop organized by Deputy for the Social Sciences of Humanity, Indonesian Institute of Sciences, August, 13, 2020

[7] F. Michel: How many photos are uploaded to flickr every day and month?, 2012,

https://www.flickr.com/photos/franckmich el/6855169886/

[8] V. Tayal and R. Srivastawa. 'Challenges in Mining Big Data Stream' in L.C. Jain, et al., (eds), Data and Communication Network, Advances Intelligent Systems and Computing 847, Springer Nature of Singapore, 2019, https://doi.org/10.1007/978-981-13-22549_15

[9] E. Seravinelli, 'Digital Life on Instagram New Social Communication of Photography', UK: Emerald Publishing, 2018

[10] https://netlytic.org, accessed on August-October, 2020

[11] https://github.com/strohne/Facepager

[12] B. Crawford et al. Using a Social 'Media Inspired Optimization Algorithmto Solve the Set Covering Problem', in: Meiselwitz, G. (Ed.), Social Computing and Social Media. Design, Human Bahaviour and Analytics. HCII 2019, Lecture Notes in Computer Science, vol
11578, pp. 43-52, 2019, Springer Nature Switzerland AG 2019, https://doi.org/10.1007/978-3030-21902-

4.4

[13], [14] A. Alsaeed, 'Automating Instagram Activities and Analysis: A Survey of Existing Tools', in Gabriele Meiselwith (Ed.), Social Computing and Social Media. Design, Human Behaviour and Analytics, HCII 2019, LNCS 11578, pp. 267-277, 2019, Springer Nature Switzerland AG 2019, https://doi.org/10.1007/978-3-030-219024_19

[15] J. Leskovec, A. Rajaraman, and J. Ullman. 'Mining of Massive Dataset Analysis of Large Graphs: Community Detection'. Stanford University: http://www.mmds.org

[16] R. Alhajj and J. Rokne. Encyclopedia of Social Network Analysis and Mining. Editors. Springer New York. 2018

[17] S. Zizek, 'Pandemic Covid-19 Shake The World', New York: OR Books

[18] S. Webb, 'Pandemic', in New Light Through Old Windows: Exploring Contemporary Science Through 12 Classic Science Fiction Tales, Science and Fiction, 2019, Springer Nature Switzerland AG 2019, https://doi.org/10.1007/978-3-030$\underline{03195-4 \_3}$

[19] S. Khan, and D. Humerovic, 'Psychology of the Pandemic', in D. Humerovic (Ed.), Psychiatriy of Pandemics, 2019, Springer Nature Switzerland AG 2019, https://doi.org/10.1007/978-030-15346$\underline{53}$

[20] M. Davis, Uncertainty and Immunity in Public Communication on Pandemics, in K. Bjorkdahl, B. Carlsen, Editors, Pandemics, Publics, and Politics, Palgrave Pivot, Singapore, 2019, https://doi.org/10.1007/978-981-13-2802$\underline{2} 3$

[21] K. Bjorkdahl, B. Carlsen, 'Enacting Pandemics: How Health Authorities Use 
the Press---And Vise Versa', in K. Bjorkdahl, B. Carlsen (Eds.), Pandemics, Publics, and Politics, Palgrave Pivot, Singapore, 2019, https://doi.org/10.1007/978-981-13-2802$\underline{2} 4$

[22] Wijayanto, and I. Fahmi, 'Normalising New Normal? Public Opinion Manipulation on Social Media to Support The New Normal Policy in Indonesia', presentation at ISEAS Yusof Ishak Institute Webinar, Media, Technology, and Society Programme \& Indonesia Studies Programme, October, 26, 2020, https://www.iseas.edu.sg

[23] A.I. Al-Dawis, Choe P., 'A Framework of Information Security Integrated with Human Factors, in Moallem A., Ed., HCI for Cybersecurity, Privacy and Trust, HCII 2019, Lecture Notes in Computer Science, vol. 11594, Springer, Cham, https://doi.org/10.1007/978-3-030-223519_15

[24] L. Xue, and G. Zeng, Global Strategies and Response Measures to the Influenza A (H1N1) Pandemic, in A Comprehensive Evaluation on Emergency Response in China, Research Series on the Chinese Dream and China's Development Path, Springer, Singapore, https://doi.org/10.1007/978-13/0644-0_2 